\title{
Social Intelligence and Academic Achievement as Predictors of Adolescent Popularity
}

\author{
Noortje Meijs - Antonius H. N. Cillessen • \\ Ron H. J. Scholte $\cdot$ Eliane Segers $\cdot$ Renske Spijkerman
}

Received: 19 June 2008 / Accepted: 18 November 2008/Published online: 9 December 2008

(C) The Author(s) 2008. This article is published with open access at Springerlink.com

\begin{abstract}
This study compared the effects of social intelligence and cognitive intelligence, as measured by academic achievement, on adolescent popularity in two school contexts. A distinction was made between sociometric popularity, a measure of acceptance, and perceived popularity, a measure of social dominance. Participants were 512, 14-15 year-old adolescents (56\% girls, 44\% boys) in vocational and college preparatory schools in Northwestern Europe. Perceived popularity was significantly related to social intelligence, but not to academic achievement, in both contexts. Sociometric popularity was predicted by an interaction between academic achievement and social intelligence, further qualified by school context. Whereas college bound students gained sociometric popularity by excelling both socially and academically, vocational students benefited from doing well either socially or academically, but not in combination. The implications of these findings were discussed.
\end{abstract}

Keywords Adolescent popularity .

Academic achievement $\cdot$ Social intelligence

N. Meijs ( $\square)$ - A. H. N. Cillessen · R. H. J. Scholte · E. Segers · R. Spijkerman

Behavioural Science Institute, Radboud Universiteit Nijmegen,

Comeniuslaan 4, 6525 HP Nijmegen, The Netherlands

e-mail: n.meijs@pwo.ru.nl

A. H. N. Cillessen

Department of Psychology, University of Connecticut,

Storrs, CT, USA

\section{Introduction}

Finding their way in the peer group is an important developmental task for adolescents. After the transition from elementary to secondary school, adolescents begin to arrange themselves in cliques, and a strong desire emerges to be included in peer activities and to be accepted by peers. With the increasing importance of affiliations with peers, a stable hierarchy of cliques develops in the broader peer network by the end of middle school (Newcomb et al. 1999). Adolescents strive to establish membership in a clique that is supportive and consistent with their personal interests and characteristics.

The place of adolescents in this network of relationships influences their further development. On the one hand, adolescents with low social status are at risk for conduct problems (Dodge and Pettit 2003; Laird et al. 2001). On the other hand, high status predicts well-being (Ostberg 2003) and healthy individual and interpersonal functioning (Hartup 1995). Popular students are prosocial and cooperative, and being popular implies power in setting the norms for desirable behavior in the peer group (Lease et al. 2002). Thus, adolescents' relationships with peers are associated with multiple aspects of development and adjustment, and high status adolescents benefit from their status in several ways. Insight in the determinants of high status or popularity in the peer group enhances our understanding of adolescent development.

Popularity can be defined in two ways (Parkhurst and Hopmeyer 1998). The first definition is sociometric popularity, or being well-liked and accepted by others. Adolescents who are sociometrically popular display high levels of prosocial and cooperative behavior and low levels of aggression. They are well-adjusted emotionally and have high-quality friendships concurrently and later (Rubin et al. 
1998). The second definition is perceived popularity, which indicates social dominance, influence, and prestige in the peer group. Whereas perceived popular adolescents may benefit from their status in the short term by controlling resources (Hawley 2003), less is known about the longterm consequences associated with perceived popularity (Cillessen and Rose 2005). Studies that investigated both sociometric and perceived popularity found that they are moderately related (Cillessen and Mayeux 2004; de Bruyn and Cillessen 2006a, b; LaFontana and Cillessen 1998; Lease et al. 2002; Parkhurst and Hopmeyer 1998). This underlines the importance of measuring both constructs separately when studying popularity in adolescence.

\section{Determinants of Popularity}

Being a popular member of the peer group, either sociometrically or perceived, is based on many factors. Sociometrically popular adolescents are mainly characterized in positive ways. Newcomb et al. (1993) found sociometrically popular adolescents to behave in prosocial ways, excel in academic skills, and exhibit low levels of aggression and social withdrawal. Rodkin et al. (2000) found that sociometrically popular boys are seen as prosocial, nonaggressive, and studious. Perceived popular adolescents demonstrate both positive and negative qualities. They are characterized as cool, powerful, influential, arrogant, exclusionary, elitist, manipulative, controlling, and aggressive (Adler and Adler 1998; Eder 1985; Lease et al. 2002; Parkhurst and Hopmeyer 1998). Furthermore, they tend to engage in highly visible and prestigious activities such as cheerleading and athletics, often have expensive clothes and possessions, and are physically attractive (Adler and Adler 1998; LaFontana and Cillessen 2002; Lease et al. 2002); Adler et al. (1992) found that the determinants of perceived popularity vary by gender. For example, boys achieve high status on the basis of athletic ability, coolness, toughness, social skills, and success in cross-gender relationships. Girls gain perceived popularity because of their parents' socioeconomic status and their own physical appearance, social skills, and academic success. As can be concluded from this list, most studies on the determinants of popularity have focused either on social behaviors (e.g., aggression or cooperation), or on stable external attributes (such as physical attractiveness, athletic ability, or socioeconomic status).

Important determinants of peer status can also be found in the social-cognitive domain. Although the association between social cognition and peer rejection has been the focus of attention of many researchers (e.g., Dodge 1986), fewer studies have looked at the association between social-cognitive skills and popularity, especially in adolescence. One construct in the social-cognitive domain that seems highly relevant to popularity is social intelligence. It seems that popular students, either sociometric or perceived, have the knowledge and skills to behave in ways that lead to high status. Sociometrically popular adolescents behave in prosocial ways and know how to maintain positive relations with peers. Perceived popular adolescents do not always behave in prosocial ways, as they can be aggressive and manipulative, but they do seem to know how to use their social skills effectively. Knowing how to maintain high status indicates an ability to understand the goals, needs, and intentions of others in social situations, and to behave accordingly. The first goal of this study was to further examine the role of social intelligence in high peer group status by determining its unique contributions to sociometric versus perceived popularity.

An important question is whether the effects of social intelligence on popularity are primarily an effect of intelligence that has little to do with uniquely social abilities. Indeed, popularity is often correlated with indicators of intelligence. For example, Newcomb et al. (1993) demonstrated that sociometric popularity is positively correlated with cognitive and academic competencies in many studies. LaFontana and Cillessen (2002) found positive associations between perceived popularity and academic achievement. However, we hypothesize that the effects of social intelligence on popularity cannot be reduced to an effect of intelligence, but are also uniquely determined by social-cognitive skills that cannot be reduced to cognitive skills. Therefore, our second goal was to examine the association of academic abilities (as an operational definition of $\operatorname{cog}$ nitive ability) with popularity, and the association of social intelligence with popularity while academic ability is controlled.

\section{Social Intelligence and Popularity}

The relationship between social intelligence and popularity appears to be positive for both boys and girls. Sociometrically popular students are prosocial and helpful to their peers (Coie and Kupersmidt 1983). They have a behavioral repertoire (social problem-solving skills, positive social actions, prosocial traits) that promotes success in friendships (Newcomb et al. 1993). Overall, sociometrically popular students show high levels of sociability and low levels of withdrawal. Perceived popular students are especially socially visible. Adler et al. (1992) found that adolescents' perceived popularity reflects social intelligence in that they seem to have some kind of social control. For both boys and girls, perceived popularity is accompanied by admiration, leadership, and the ability to manipulate and control the social order of the peer group (Adler and Adler 1998). 
Some gender differences have been found as well. Boys tend to know how to use their social skills effectively, resulting in friendships that enhance their perceived popularity. As a desire for popularity exists, boys also tend to be manipulative, domineering, and controlling. Adler et al. (1992) further demonstrated that boys who have extremely poor social and interpersonal skills often have difficult social lives and low perceived popularity. Girls who are perceived as popular are viewed as prosocial, socially visible, and using social-aggressive strategies to establish and maintain a popular status.

Based on these studies, the association between social intelligence and both types of popularity is expected to be positive. It is expected that both sociometric and perceived popularity at least partly rest on social intelligence. These studies also suggest that gender should be taken into account when examining the associations between social intelligence and sociometric and perceived popularity.

\section{Academic Achievement and Popularity}

The relationship between academic achievement and popularity appears to differ for both types of popularity. Academic achievement and sociometric popularity are usually positively related: on average, well-liked students perform better than students low in acceptance (Frentz et al. 1991; Hatzichristou and Hopf 1996; Wentzel 1991). The relationship between academic achievement and perceived popularity is mixed. Some studies found that perceived popular students perform well at school (e.g., LaFontana and Cillessen 2002). Other studies found the opposite (e.g., Adler et al. 1992; Hopmeyer Gorman et al. 2002). LaFontana and Cillessen (2002) conducted a sociometric study with 4th through 8th grade inner-city students in an ethnically diverse, lower-middle class community. They found that perceived unpopular students were often described as less academically able and competent. Hopmeyer Gorman et al. (2002) conducted a comparable study with 351 students in an ethnically diverse urban community. In their study, perceived popularity was related to low academic achievement. Perceived popular students have thus been classified both in positive and in negative terms with regard to their academic performance.

Because the above described studies used comparable samples and methods, it is unclear why opposing results were found. One reason may be that these studies differed in the degree to which they controlled for social intelligence. In the current study, the unique associations of social intelligence and academic skills with popularity are considered, controlled for each other's influence. There is also some evidence that the association of academic achievement with perceived popularity is further qualified by gender. Adler et al. (1992) found that academic skills were correlated negatively with perceived popularity for boys, indicating that they may suffer negative stigma from performing well academically, but positively for girls, indicating that they tend to gain status from performing well in school. Adler and Adler (1998) found that perceived popular boys felt that they had to hide their academic interests. Based on these results, we expected that sociometric popularity is positively related to academic achievement for both genders, but that the association of perceived popularity with academic achievement is positive for girls, but negative for boys.

Combining Social Intelligence and Academic Achievement

In addition to examining the main effects of social intelligence and academic achievement on sociometric and perceived popularity, the interaction between social intelligence and academic achievement was tested. It is possible that students who are both socially intelligent and highly achieving are the most well-liked or the most popular students in their school. However, it is also possible that whereas social intelligence has a positive effect on perceived popularity, the effect of academic achievement may be neutral or even negative. In this case, the most popular students may be highly socially intelligent but not necessarily doing well in school. To clarify this matter, we also examined the interaction between social intelligence and academic achievement in the prediction of popularity.

\section{Role of Social Context}

It can be expected that social intelligence will always have a positive effect on popularity, no matter what the nature of the peer group is. Social intelligence implies adjusting one's behavior to the norms of the group. No matter what these norms are, the socially intelligent adolescent is always expected to be able to read them accurately and adjust to them. This process is always expected to be beneficial to their status in the group.

In contrast, the effect of academic achievement on peer status is expected to depend on the norms of the group. Academic achievement is expected to lead to higher status only if it is prioritized in the classroom. In peer groups where academic excellence is the norm, such as in classrooms with a high academic orientation, it is expected to lead to popularity. But in classrooms where other skills are prioritized, academic achievement may not lead to popularity or even be predictive of unpopularity. Different types of classrooms may thus have different associations between academic achievement and popularity. 
In the current study, two educational contexts were considered: college preparatory classrooms and vocational track classrooms. Whereas the former prepare students for a college education, the latter prepare them for a specific vocation or occupation. The norms for academic achievement differ between these contexts. Academic achievement is valued in college preparatory classrooms (Berends 1995). In vocational classrooms, academic achievement may instead be seen as nerdy and uncool. Therefore, it was expected that educational level (vocational vs. college preparatory) moderates the effect of academic achievement on popularity. It was expected that academic achievement positively predicted sociometric and perceived popularity in college preparatory classrooms, but that these effects are absent or even negative in vocational classrooms.

\section{Research Goals and Hypotheses}

This study had four goals. The first goal was to examine the unique effects of social intelligence on sociometric and perceived popularity. It was hypothesized that social intelligence would positively predict both. The second goal was to examine the unique effects of academic achievement on sociometric and perceived popularity. It was hypothesized that academic achievement would positively predict sociometric popularity for boys and girls, but that the effect of academic achievement on perceived popularity would vary by gender: positive for girls but weaker or negative for boys. The third goal was to examine the interactive effects of social intelligence and academic achievement on both forms of popularity. The fourth and final goal was to examine school context as a moderator, by comparing a setting with a strong academic focus (college preparatory classrooms) with a setting with a lesser focus on academic achievement (vocational classrooms). It was hypothesized that the effects of social intelligence would be identical in both contexts, but that the effects of academic achievement would vary. Academic achievement was hypothesized to be more strongly related to popularity in classrooms where academic excellence is the norm.

\section{Method}

Participants and Procedure

The data were collected as part of a larger study on peer relations and popularity, conducted in November 2007. Participants were 512 students $(M$ age $=14.9$ years, $\mathrm{SD}=.60 ; 56 \%$ girls, $44 \%$ boys) in 22 third-year classrooms of 22 junior high schools serving middle-class communities in The Netherlands. The average number of adolescents per classroom was 23, typical for schools in this system (Ma and Koenker 2006). The participation rate was high. The students in this sample represented $88 \%$ of the total number of students enrolled in these classrooms. The classrooms were of two educational levels: $55 \%$ of the participants were in college preparatory classrooms, the remaining $45 \%$ in vocational track classrooms. The majority of the participants $(>90 \%)$ were of Caucasian descent.

The data collection took place during regular 50-min classroom sessions and consisted of a peer sociometric measure and a self-report measure. Before completing the measures, students were explained the confidentiality of their answers. Students obtained parental permission to participate and assented to participate on the day of data collection.

Measures

\section{Popularity}

Popularity was measured with peer nominations for four questions: liked most, liked least, most popular, and least popular. Unlimited peer nominations were used within classrooms. The number of nominations received for each question was counted for each student and standardized to $z$-scores within classrooms to control for differences in classroom size. A score for sociometric popularity was computed for each student by taking the difference between the standardized liked most and liked least scores, and again standardizing the resulting difference scores within classrooms. A score for perceived popularity was obtained by taking the difference between the standardized most popular and least popular scores, again standardizing the resulting difference scores.

\section{Academic Achievement}

Academic achievement was measured with three selfreport items concerning general school performance. Students were asked to rate: (1) their average grade across all classes they were currently taking; (2) their most recent report card grade for math; and (3) their most recent report card grade for language education. Report card grades for math and language education were chosen because students are well aware of where they stand in terms of their quantitative and language skills. Furthermore, students have a good general sense of their overall school performance, that includes a range of other subjects in addition to math and language classes. Therefore, a third item was included asking students to rate their average grade across all their classes.

In this academic system, grades are on a continuous scale from 0 to 10 , with 10.0 indicating a perfect score. 
Grades between 9.0 and 10.0 are comparable to grades in the A range in the U.S. system, between 8.0 and 9.0 to B, between 7.0 and 8.0 to $\mathrm{C}$, and between 6.0 and 7.0 to $\mathrm{D}$. Grades less than 6.0 are failing. The mode of the distribution of grades is around 7.0. A grade around 7.0 is considered an average grade. For each of the three questions, students indicated their grades on a 5-point scale: $1=$ less than 5 (clearly failing); $2=$ between 5 and 6 (failing); 3 = between 6 and 7 (average); $4=$ between 7 and 8 (above average); and $5=$ higher than 8 (good to very good). A composite academic achievement score was computed by averaging the three ratings $(M=3.22$, $\mathrm{SD}=.76, \alpha=.62$ ).

\section{Social Intelligence}

Social intelligence was measured with the 21-item Tromso Social Intelligence Scale, a measure that is relatively free of social desirability bias (Silvera et al. 2001). The scale includes three 7-item subscales of social intelligence: social information processing $(\alpha=.80)$, social skills $(\alpha=.79)$, and social awareness $(\alpha=.72)$. Each item describes a social ability or skill (e.g., "I can predict other people's behavior"). Students rated on a 7-point scale how well they were able to perform each skill $(1=$ extremely poor, $7=$ extremely well). A reliable composite social intelligence score was computed by averaging the 21 items $(M=4.79, \mathrm{SD}=.67, \alpha=.82)$.

\section{Results}

\section{Preliminary Analysis}

Table 1 shows the means and standard deviations of the study variables by gender. A 2 (Gender) ANOVA was conducted for each variable and Cohen's $d$ was computed. Girls scored significantly higher than boys on social intelligence, whereas boys scored significantly higher than girls on perceived popularity. The size of these effects was small. There was no significant gender difference for academic achievement or sociometric popularity.
Table 2 Correlations among main study variables by gender

\begin{tabular}{lrccc}
\hline & 1 & 2 & 3 & \multicolumn{1}{l}{4} \\
\hline 1. Academic achievement & & -.05 & -.05 & .08 \\
2. Social intelligence & .10 & & $.31^{*}$ & $.19^{*}$ \\
3. Perceived popularity & -.01 & $.20 *$ & & $.57^{*}$ \\
4. Sociometric popularity & .04 & .13 & $.33^{*}$ &
\end{tabular}

Note: $* p<.05$. Correlations that are italicized were significantly different by gender, $p<.001$. Correlations for boys are below the diagonal, correlations for girls above the diagonal

Table 2 presents the correlations between the study variables by gender. Gender differences were tested with Fisher's $r$-to- $Z$ test for independent correlations. For both genders, sociometric and perceived popularity were positively correlated. This correlation was stronger for girls (.57) than for boys (.33). Social intelligence correlated positively with perceived popularity for both genders. For girls, social intelligence also correlated with sociometric popularity, but not for boys. Academic achievement did not correlate significantly with social intelligence or the two measures of popularity for either gender.

\section{Regression Analysis Strategy}

To examine the effects of social intelligence and academic achievement on sociometric and perceived popularity, a hierarchical regression was run for each type of popularity. In Step 1, gender (dummy coded: girls $=1$, boys $=0$ ), educational level (dummy coded: college preparatory $=1$, vocational $=0$ ), and their interaction were entered. To control for the correlation between the two forms of popularity, perceived popularity was entered in Step 2 of the model predicting sociometric popularity, and sociometric popularity was entered in Step 2 of the model predicting perceived popularity. In Step 3 of both models, academic achievement, social intelligence, and their interaction were entered. In Step 4, six terms were entered that tested whether the main effects of social intelligence and academic achievement were moderated by gender, educational level, or both. Finally, in Step 5, three terms were entered that tested whether the interaction between social

Table 1 Means and standard deviations for main study variables by gender

\begin{tabular}{|c|c|c|c|c|c|}
\hline & \multicolumn{2}{|c|}{ Boys $(N=225)$} & \multicolumn{2}{|c|}{ Girls $(N=287)$} & \multirow[t]{2}{*}{ Effect size Cohen's $d$} \\
\hline & $M$ & SD & $M$ & SD & \\
\hline Academic achievement (GPA) & 3.16 & .71 & 3.28 & .79 & .16 \\
\hline Social intelligence & 4.69 & .66 & 4.87 & .67 & .27 \\
\hline Perceived popularity & .11 & .90 & -.09 & 1.04 & .21 \\
\hline Sociometric popularity & -.02 & .95 & .02 & 1.01 & .04 \\
\hline
\end{tabular}

Note: Means that are italicized were significantly different by gender, $p<.05$ 
intelligence and academic achievement was further moderated by gender, educational level, or both.

Prediction of Sociometric Popularity

The results for the model predicting sociometric popularity are shown in Table 3. As can be seen, the model predicted $28 \%$ of the variance in sociometric popularity. In Step 2, perceived popularity significantly and uniquely predicted $23 \%$ of the variance. Consistent with the correlation between both constructs, perceived popularity positively predicted sociometric popularity. Step 5 was also significant, uniquely predicting an additional $2 \%$ of the variance. This effect was due to a significant interaction between educational level, social intelligence, and academic achievement. In order to understand this effect, the social intelligence by academic achievement interaction was plotted separately for students in both high school tracks following the procedures of Aiken and West (1991; see also Holmbeck 2002).

Figure 1 shows the interaction between social intelligence and academic achievement for the vocational track. In this school context, academic achievement had no effect

Table 3 Regression results predicting sociometric popularity from gender, education, perceived popularity, social intelligence, and academic achievement

\begin{tabular}{|c|c|c|c|c|}
\hline & $\Delta R^{2}$ & $b$ & SE & $\beta$ \\
\hline Step 1 & .00 & & & \\
\hline Gender & & .07 & .13 & .04 \\
\hline Education & & -.02 & .14 & -.01 \\
\hline Gender $\times$ education & & -.10 & .18 & -.05 \\
\hline Step 2 & $.23 *$ & & & \\
\hline Perceived popularity & & $.47 *$ & .04 & $.49 *$ \\
\hline Step 3 & .01 & & & \\
\hline Social intelligence & & .04 & .04 & .04 \\
\hline Academic achievement & & .07 & .04 & .08 \\
\hline $\mathrm{AA} \times \mathrm{SI}$ & & .03 & .04 & .03 \\
\hline Step 4 & .02 & & & \\
\hline Gender $\times$ SI & & -.08 & .12 & -.06 \\
\hline Gender $\times$ AA & & .24 & .13 & .19 \\
\hline Education $\times$ SI & & .05 & .12 & .03 \\
\hline Eduction $\times$ AA & & .11 & .13 & .09 \\
\hline Gender $\times$ education $\times$ SI & & .22 & .16 & .12 \\
\hline Gender $\times$ education $\times$ AA & & -.27 & .17 & -.18 \\
\hline Step 5 & $.02 *$ & & & \\
\hline Gender $\times$ SI $\times$ AA & & .12 & .12 & .10 \\
\hline Education $\times$ SI $\times$ AA & & $.43 *$ & .13 & $.32 *$ \\
\hline Gender $\times$ education $\times$ SI $\times$ AA & & -.28 & .16 & -.17 \\
\hline Total $R^{2}$ & $.28 *$ & & & \\
\hline
\end{tabular}

Note: $* p<0.05$. AA academic achievement, SI social intelligence

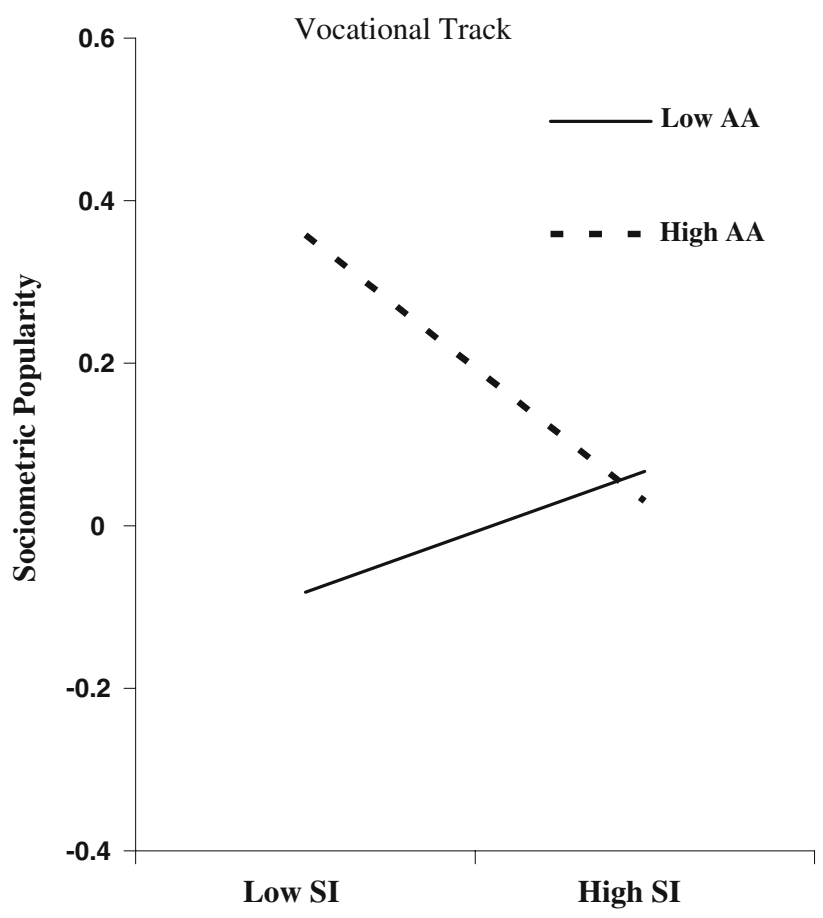

Fig. 1 Interaction between social intelligence (SI) and academic achievement (AA) in the prediction of sociometric popularity in vocational track classrooms

on sociometric popularity at high levels of social intelligence, but a strong effect at low levels of social intelligence. Students who did not do well in school and were not very intelligent socially were the least liked by their peers. Students who did well in school but were not very intelligent socially were the most liked by their peers. Put differently, social intelligence had a positive effect on liking by peers for students low in academic achievement, but a negative effect for students high in academic achievement.

Figure 2 shows the interaction for the college preparatory track. Here, the effect was reversed: academic achievement had almost no effect on sociometric popularity at low levels of social intelligence, but a strong effect at high levels of social intelligence. In this context, students who did well in school and were socially intelligent were the most liked, whereas students who did well in school but were not very intelligent socially were the least liked.

\section{Prediction of Perceived Popularity}

The model predicting perceived popularity is shown in Table 4. This model predicted $31 \%$ of the variance in perceived popularity. Step 2, including sociometric popularity, was significant, predicting $23 \%$ of the variance. Not surprisingly, sociometric popularity positively predicted perceived popularity. Step 3 was also significant, explaining an additional $4 \%$ of the variance. This effect was due to 


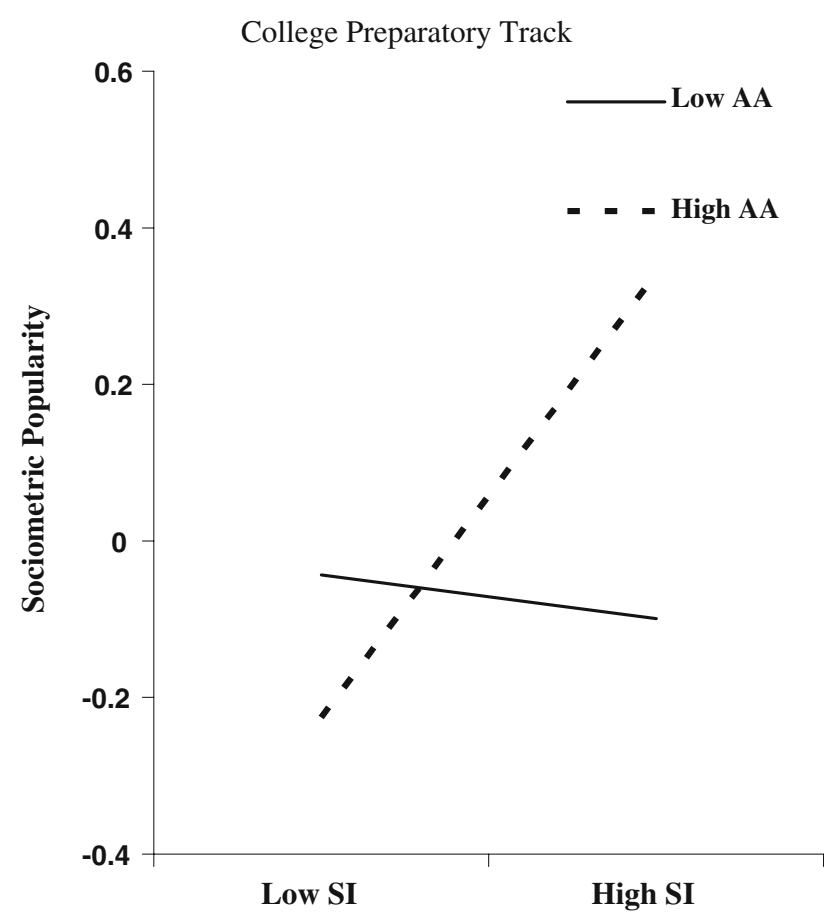

Fig. 2 Interaction between social intelligence (SI) and academic achievement (AA) in the prediction of sociometric popularity in college preparatory classrooms

a significant main effect of social intelligence. Social intelligence significantly and uniquely predicted perceived popularity, over and beyond the effects of gender, educational level, and sociometric popularity. This effect was not further moderated by any of the other predictors.

\section{Discussion}

The overall goal of this study was to investigate the associations of academic achievement and social intelligence with popularity in two school contexts. Two types of popularity were distinguished: sociometric and perceived popularity. Whereas sociometric popularity is a measure of peer acceptance, perceived popularity is a measure of visibility, dominance, and prestige in the peer group. Consistent with earlier studies (Cillessen and Mayeux 2004; de Bruyn and Cillessen 2006a, b; LaFontana and Cillessen 1998; Lease et al. 2002), sociometric and perceived popularity were moderately correlated. Further, different predictive effects were found for both types of high status in the peer group.

The first specific goal of this study was to examine the association between social intelligence and both types of popularity. Consistent with the hypotheses, social intelligence and perceived popularity were correlated, but unexpectedly, social intelligence and sociometric popularity were not related. No gender differences were found.
Table 4 Regression results predicting perceived popularity from gender, education, sociometric popularity, social intelligence, and academic achievement

\begin{tabular}{|c|c|c|c|c|}
\hline & $\Delta R^{2}$ & $b$ & SE & $\beta$ \\
\hline Step 1 & .02 & & & \\
\hline Gender & & -.34 & .14 & -.19 \\
\hline Education & & -.16 & .14 & -.08 \\
\hline Gender $\times$ education & & .32 & .19 & .15 \\
\hline Step 2 & $.23 *$ & & & \\
\hline Sociometric popularity & & $.50 *$ & .04 & $.48 *$ \\
\hline Step 3 & $.04 *$ & & & \\
\hline Social intelligence & & $.20 *$ & .04 & $.20 *$ \\
\hline Academic achievement & & -.06 & .04 & -.07 \\
\hline $\mathrm{AA} \times \mathrm{SI}$ & & -.03 & .04 & -.03 \\
\hline Step 4 & .01 & & & \\
\hline Gender $\times$ SI & & .24 & .12 & .18 \\
\hline Gender $\times$ AA & & -.16 & .13 & -.13 \\
\hline Education $\times$ SI & & .11 & .12 & .08 \\
\hline Eduction $\times$ AA & & -.00 & .13 & -.00 \\
\hline Gender $\times$ education $\times$ SI & & -.26 & .16 & -.14 \\
\hline Gender $\times$ education $\times$ AA & & .18 & .17 & .11 \\
\hline Step 5 & .01 & & & \\
\hline Gender $\times$ SI $\times$ AA & & -.08 & .12 & -.07 \\
\hline Education $\times \mathrm{SI} \times \mathrm{AA}$ & & -.22 & .13 & -.16 \\
\hline Gender $\times$ education $\times \mathrm{SI} \times \mathrm{AA}$ & & .06 & .17 & .04 \\
\hline Total $R^{2}$ & $.31 *$ & & & \\
\hline
\end{tabular}

Note: $* p<0.05$. AA academic achievement, SI social intelligence

Thus, being socially intelligent has implications for adolescents' dominance status in the peer group, but not for the degree to which they are liked by their peers.

Although our findings were not entirely as hypothesized, we do believe they make sense. The association between perceived popularity and social intelligence was predicted earlier by Adler and Adler (1998); Adler et al. (1992); Lease et al. (2002). Our study supports the view that students who are socially savvy and effective, have a high degree of social awareness, or are good at processing social intelligence (the three aspects of social intelligence present in our scale), are likely to become visible and popular in the peer group. However, they are not necessarily liked and accepted. One reason for this difference may be that social intelligence influences how an adolescent interacts in the peer group at large, whereas liking is a dyadic evaluation. Mount et al. (1998) already have indicated that personality traits important for teamwork differ from those important for tasks involving dyadic interactions. The fact that social intelligence, (defined as the ability to understand the social world well and act accordingly) predicts status at the group level, but not necessarily liking at the dyadic level, may be a quite logical finding. 
Related to these issues, it may be interesting in future research to further examine different subdomains of social intelligence, rather than considering it as one homogeneous construct as we did. It is possible that different aspects of social intelligence are differentially related to both forms of popularity. For example, it is possible that social intelligence skills, such as the ability to accurately read a peer's emotions and respond appropriately and empathically, are strongly related to liking and acceptance (cf. Lopes et al. 2004) but not to dominance. Conversely, such social sensitivities and fine-tuning may reduce one's chances of becoming powerful and influential rather than increase them. Other aspects of social intelligence could also be considered. Such research would require additional measures of social intelligence. We measured social intelligence rather generally with a self-report measure. To examine the detailed subcomponents of social intelligence however, other measures would be needed that do not rely only on adolescents' self reports.

The second goal of this study was to address the unique effects of academic achievement on both types of high status. Academic achievement did not have a main effect on either sociometric or perceived popularity, and, in contrast to other studies (e.g., Adler et al. 1992), no differentiation by gender was found. Thus, controlling for social intelligence cannot explain why some studies have found a positive link between academic achievement and perceived popularity (e.g., LaFontana and Cillessen 2002), and others the opposite (e.g., Hopmeyer Gorman et al. 2002). The lack of effects in the current study may be due to the fact that we focused on high school students. Academic achievement is a predictor of social status in elementary and middle school (e.g., Lease et al. 2002), with different results for boys and girls. At older ages, other variables may take over as the primary predictors of peer status. For example, due to physical maturation and the emerging interest in romantic relationships, physical attractiveness and appearance may overrule the predictive effect of academic achievement.

Although main effects of academic achievement were not found, it did play a role when educational level and social intelligence were also taken into account, as was done in the analyses for the remaining two goals of this study. Combining the effects of social intelligence and academic achievement on both forms of popularity was the third goal of this study; examining the role of school context was the fourth and final goal. Contrary to the hypotheses, there was no interaction between social intelligence and academic achievement in the prediction of perceived popularity. For the prediction of sociometric popularity, however, this interaction was found and it was further qualified by educational context: the interaction between social intelligence and academic achievement appeared to differ between vocational and college preparatory classrooms.

In vocational classrooms, peer acceptance decreased when social intelligence and academic achievement were both high. For vocational students with low academic achievement, sociometric popularity increased slightly when social intelligence was higher. In this context, social intelligence seemed to enhance peer acceptance only when academic achievement was low. In college preparatory classrooms, peer acceptance increased when social intelligence and academic achievement were both high. For college bound students with low academic achievement, peer acceptance decreased slightly when social intelligence was higher. In this context, social intelligence enhanced peer acceptance when academic achievement was also high. In summary, in college preparatory classrooms, the combination of high academic achievement and high social intelligence was the most beneficial. In vocational classrooms, the combination of high social intelligence and low academic achievement was the most beneficial.

For a college bound student to be liked and accepted, it appears to be not enough to achieve well academically. An appropriate level of social intelligence is also needed. The college preparatory track is highly focused on academics: compared to vocational-track students, college preparatory students have high college expectations and are academically engaged (cf. Berends 1995). Because academic achievement is highly valued in this context, students who do not do well academically may be rejected, irrespective of their social intelligence. Because everyone is academically focused, achievement does not contribute much to popularity, but social intelligence does.

Of course, it is also possible that the causal arrow points the other way and that students who are well-accepted by their peers and highly socially skilled subsequently do well in school, because school is a pleasant environment for them in which they feel comfortable and accepted and not distracted by the stressors of peer rejection. This is consistent with Wentzel and Caldwell's (1997) findings that well-accepted students benefit more from resources to promote academic achievement than rejected students, and thereby enhance their academic performance. Less accepted students also may not perform well academically because they do not know how to use the available resources. Although socially intelligent, they may fail in their attempts to use their peers as a resource because of their less-accepted status, and thereby become even less accepted. More research is needed to further clarify the direction of influence responsible for the interaction between social intelligence and academic achievement for college bound students.

For vocational students, academic achievement did not lead to acceptance, but when combined with social 
intelligence, popularity decreased. Vocational students who do well academically and socially were relatively unpopular. It may be more difficult for them to maintain friendships, because there are fewer like-minded peers in their school. Friends can help each other in many ways, for example by providing support or help when needed. When in a friendship one person is superior in some areas, support may flow only in one direction towards the less superior person. In the long term, the lack of reciprocity may be detrimental to the relationship. This is consistent with Clark and Ayers' (1988) finding that adolescents with non-reciprocated friendships are seen as less attractive and have lower social status than adolescents with reciprocated friendships.

It is also possible that other students are jealous of excelling students in a context where that is not the norm. As a result of this jealousy, they may be stereotyped as "nerds." Nerds are often the least liked among adolescents (e.g., Senior and Anderson 1993). Whatever the explanation, it is clear that vocational students did not benefit from being both academically and socially skilled. In their context, only students with low academic skills benefited from their social skills. Apparently, these students compensate their low academic performance with social intelligence, and thereby gain in peer acceptance.

Thus, educational level matters for the prediction of sociometric popularity from academic achievement and social intelligence. As hypothesized, adolescents in college preparatory classrooms who were both socially intelligent and academically successful had the highest status. Academic achievement predicted high status for college bound students, but social intelligence explained part of the effect. In vocational classrooms, excelling both socially and academically did not lead to high status. Students in these classrooms benefited from doing well either socially or academically, but not in combination.

There were some limitations to this study. The crosssectional and correlational nature of the data precludes us from making strong causal statements. For example, it is not possible to determine if sociometric popularity is influenced by academic achievement, or the other way round. Sociometrically popular students may become academically skilled because of their high status and the accompanying privileges that promote their academic success, or they might be liked because of their academic success. Longitudinal data are needed to clarify the direction of influence behind these associations.

Another limitation is a noted discrepancy with earlier research. Studies with adolescents typically find that the correlation between sociometric and perceived popularity is lower for girls than for boys, that is, the two constructs are usually more separate for adolescent girls than for boys (Cillessen and Borch 2006; Cillessen and Mayeux 2004). In the current study, however, the correlation was lower for boys than for girls. This may be due to cultural differences. The present study was conducted in The Netherlands, whereas the findings from previous studies are predominantly from American samples. It seems that being wellliked and being popular are less compatible social roles for American early adolescent girls than for Dutch girls. For boys, the pattern is reversed. Perhaps competition for popularity is fiercer among adolescent girls in American middle and high schools (cf. Cillessen and Borch 2006), but fiercer among adolescent boys in European schools. The discrepancy in results could also be due to methodological issues. In the American adolescent studies, the entire grade is usually the reference group for sociometric choices (e.g., Cillessen and Borch 2006; Cillessen and Mayeux 2004). In the current European study, the classroom was the reference group. The nature of the reference group may matter less for judgments of popularity in the peer group at large, than for dyadic judgments of liking.

Further research is needed to compare students from different educational levels with each other. It is still unclear whether differences in predictors of both types of popularity are due to differences in grades and school types (i.e., elementary and middle school vs. high school). It is also important to gain more information about the comparison of educational levels within grades and school types. It would be interesting to know if college bound students use their social intelligence in ways that promote academic achievement. If so, less academically gifted students could benefit from social intervention programs instead of receiving academic assistance.

The present study yielded new insights into the determinants of popularity. As predicted, different factors underlie the two types of popularity. When predicting perceived popularity in high school, social intelligence plays a role. When predicting sociometric popularity, social and academic skills play a role, and especially in combination. Their effects are further moderated by school context. If in college preparatory classrooms social intelligence promotes academic achievement, teachers and policy makers should focus more on the social development of their students, in addition to their academic achievement. Social intelligence may not be entirely malleable, but is at least partly open to change. For example, social skills training can increase students' ability to perform key social behaviors that are important for social success (Spence 2003). Such interventions may not only improve adolescents' position in the peer group and reduce the problems that result from being rejected. Promoting social intelligence may also enhance academic progress, with all its positive consequences for further development.

Acknowledgments We gratefully acknowledge the participation of the students and teachers who made this project possible. 
Open Access This article is distributed under the terms of the Creative Commons Attribution Noncommercial License which permits any noncommercial use, distribution, and reproduction in any medium, provided the original author(s) and source are credited.

\section{References}

Adler, P. A., \& Adler, P. (1998). Peer power: Preadolescent culture and identity. New Brunswick: Rutgers University Press.

Adler, P. A., Kless, S. J., \& Adler, P. (1992). Socialization to gender roles: Popularity among elementary school boys and girls. Sociology of Education, 65, 169-187. doi:10.2307/2112807.

Aiken, L. S., \& West, S. G. (1991). Multiple regression: Testing and interpreting interactions. Thousand Oaks: Sage.

Berends, M. (1995). Educational stratification and students' social bonding to school. British Journal of Sociology of Education, 16, 327-351. doi:10.1080/0142569950160304.

Cillessen, A. H. N., \& Borch, C. (2006). Developmental trajectories of adolescent popularity: A growth curve modelling analysis. Journal of Adolescence, 29, 935-959.

Cillessen, A. H. N., \& Mayeux, L. (2004). From censure to reinforcement: Developmental change in the association between aggression and social status. Child Development, 75, 147-163. doi:10.1111/j.1467-8624.2004.00660.x.

Cillessen, A. H. N., \& Rose, A. J. (2005). Understanding popularity in the peer system. Current Directions in Psychological Science, 14, 102-105. doi:10.1111/j.0963-7214.2005.00343.x.

Clark, M. L., \& Ayers, M. (1988). The role of reciprocity and proximity in junior high school friendships. Journal of Youth and Adolescence, 17, 403-411. doi:10.1007/BF01537882.

Coie, J. D., \& Kupersmidt, J. B. (1983). A behavioral analysis of emerging social status in boys' groups. Child Development, 54, 1400-1416. doi:10.2307/1129803.

de Bruyn, E. H., \& Cillessen, A. H. N. (2006a). Heterogeneity of girls' consensual popularity: Academic and interpersonal behavioral profiles. Journal of Youth and Adolescence, 3, 435-445.

de Bruyn, E. H., \& Cillessen, A. H. N. (2006b). Popularity in early adolescence: Prosocial and antisocial subtypes. Journal of Adolescent Research, 21, 607-627. doi:10.1177/07435584062 93966.

Dodge, K. A. (1986). A social information processing model of social competence in children. In M. Perlmutter (Ed.), Minnesota symposium on child psychology (pp. 77-126). Hillsdale: Erlbaum.

Dodge, K. A., \& Pettit, G. S. (2003). A biopsychosocial model of the development of chronic conduct problems in adolescence. Developmental Psychology, 39, 349-371. doi:10.1037/00121649.39.2.349.

Eder, D. (1985). The cycle of popularity: Interpersonal relations among female adolescents. Sociology of Education, 58, 154-165. doi: $10.2307 / 2112416$.

Frentz, C., Gresham, F. M., \& Elliot, S. N. (1991). Popular, controversial, neglected, and rejected adolescents: Contrasts of social competence and achievement difference. Journal of School Psychology, 29, 109-120. doi:10.1016/S0022-4405(05) 80003-2.

Hartup, W. W. (1995). The three faces of friendship. Journal of Social and Personal Relationships, 12, 569-574. doi:10.1177/0265407 595124012.

Hatzichristou, C., \& Hopf, D. (1996). A multiperspective comparison of peer sociometric status groups in childhood and adolescence. Child Development, 67, 1085-1102. doi:10.2307/1131881.

Hawley, P. H. (2003). Prosocial and coercive configurations of resource control in early adolescence: A case for the well- adapted Machiavellian. Merrill-Palmer Quarterly, 49, 279-309. doi:10.1353/mpq.2003.0013.

Holmbeck, G. N. (2002). Post-hoc probing of significant moderational and mediational effects in studies of pediatric populations. Journal of Pediatric Psychology, 27, 87-96. doi:10.1093/jpepsy/ 27.1.87.

Hopmeyer Gorman, A., Kim, J., \& Schimmelbusch, A. (2002). The attributes adolescents associate with peer popularity and teacher preference. Journal of School Psychology, 40, 143-165. doi: 10.1016/S0022-4405(02)00092-4.

LaFontana, K. M., \& Cillessen, A. H. N. (1998). The nature of children's stereotypes of popularity. Social Development, 7, 301-320. doi:10.1111/1467-9507.00069.

LaFontana, K. M., \& Cillessen, A. H. N. (2002). Children's perceptions of popular and unpopular peers: A multimethod assessment. Developmental Psychology, 38, 635-647. doi: 10.1037/0012-1649.38.5.635.

Laird, R. D., Jordan, K., Dodge, K. A., Pettit, G. S., \& Bates, J. E. (2001). Peer rejection in childhood, involvement with antisocial peers in early adolescence, and the development of externalizing problems. Development and Psychopathology, 13, 337-354. doi: 10.1017/S0954579401002085.

Lease, A. M., Kennedy, C. A., \& Axelrod, J. L. (2002). Children's social constructions of popularity. Social Development, 11, 87109. doi:10.1111/1467-9507.00188.

Lopes, P. N., Brackett, M. A., Nezlek, J. B., Schutz, A., Sellin, I., \& Salovey, P. (2004). Emotional intelligence and social interaction. Personality and Social Psychology Bulletin, 30, 1018-1034. doi: $10.1177 / 0146167204264762$.

Ma, L., \& Koenker, R. (2006). Quantile regression methods for recursive structural equation models. Journal of Econometrics, 135, 471-506. doi:10.1016/j.jeconom.2005.07.003.

Mount, M., Barrick, M. R., \& Stewart, G. L. (1998). Five-factor model of personality and performance in jobs involving interpersonal interactions. Human Performance, 11, 145-165. doi: 10.1207/s15327043hup1102\&3_3.

Newcomb, A. F., Bukowski, W. M., \& Bagwell, C. L. (1999). Knowing the sounds: Friendship as a developmental context. In W. A. Collins \& B. Laursen (Eds.), Relationships as developmental contexts: The Minnesota symposia on child psychology (Vol. 30, pp. 63-84). Mahwah: Erlbaum.

Newcomb, A. F., Bukowski, W. M., \& Pattee, L. (1993). Children's peer relations: A meta-analytic review of popular, rejected, neglected, controversial, and average sociometric status. Psychological Bulletin, 113, 99-128. doi:10.1037/0033-2909.113. 1.99 .

Ostberg, V. (2003). Children in classrooms: Peer status, status distribution and mental well-being. Social Science and Medicine, 56, 17-29. doi:10.1016/S0277-9536(02)00006-0.

Parkhurst, J. T., \& Hopmeyer, A. G. (1998). Sociometric popularity and peer-perceived popularity: Two distinct dimensions of peer status. The Journal of Early Adolescence, 18, 125-144. doi: 10.1177/0272431698018002001.

Rodkin, P. C., Farmer, T. W., Pearl, R., \& Van Acker, R. (2000). Heterogeneity of popular boys: Antisocial and prosocial configurations. Developmental Psychology, 36, 14-24. doi:10.1037/ 0012-1649.36.1.14.

Rubin, K. H., Bukowski, W. M., \& Parker, J. G. (1998). Peer interactions, relationships, and groups. In: W. Damon (Series Ed.) \& N. Eisenberg (Vol. Ed.), Handbook of child psychology. Social, emotional, and personality development vol. 3 (pp. 619700). New York: Wiley.

Senior, A. M., \& Anderson, B. T. (1993). Who's who among AfricanAmerican student groups in high school: An exploratory investigation on peer subcultures. The Urban Review, 25, 233249. doi:10.1007/BF01112110. 
Silvera, D. H., Martinussen, M., \& Dahl, T. I. (2001). The tromso social intelligence scale. A self-report measure of social intelligence. Scandinavian Journal of Psychology, 42, 313319. doi:10.1111/1467-9450.00242.

Spence, S. H. (2003). Social skills training with children and young people: Theory, evidence and practice. Child and Adolescent Mental Health, 8, 84-96. doi:10.1111/1475-3588.00051.

Wentzel, K. R. (1991). Relations between social competence and academic achievement in early adolescence. Child Development, 62, 1066-1078. doi:10.2307/1131152.

Wentzel, K. R., \& Caldwell, K. (1997). Friendships, peer acceptance, and group membership: Relations to academic achievement in middle school. Child Development, 68, 1198-1209.

\section{Author Biographies}

Noortje Meijs is a Research Master candidate in Behavioural Science at the Radboud Universiteit Nijmegen. Her research interests include social relations in adolescence, adolescent development and the effect of cultural differences.

Antonius H. N. Cillessen is professor and chair of developmental psychology in the Behavioural Science Institute at the Radboud
Universiteit Nijmegen, The Netherlands and a senior research scientist in the Department of Psychology at the University of Connecticut. His research interests include peer relationships and peer interaction in middle childhood and early adolescence, development of aggression and antisocial behavior, developmental social psychology (small groups and interpersonal perception), and research methods for developmental psychology (sociometric methods, social network analysis, observational research, longitudinal design and analysis).

Ron H. J. Scholte is Associate Professor in the Behavioural Science Institute at the Radboud Universiteit Nijmegen. His areas of interest are social relationships in adolescence, bullying and victimization, adolescent development and adjustment.

Eliane Segers is Assistant Professor in the Behavioural Science Institute at the Radboud Universiteit Nijmegen. Her area of interest lies in the field of learning problems.

Renske Spijkerman is Post-doc researcher at the Behavioural Science Institute of the Radboud Universiteit Nijmegen. Her area of interest lies in the field of adolescent's substance use and social relations. 